\title{
Developmental Changes in the Subcellular Localization of Calretinin
}

\author{
Nicola J. Hack, Mark C. Wride, Kathleen M. Charters, Stanley B. Kater, and Thomas N. Parks \\ Department of Neurobiology and Anatomy, University of Utah School of Medicine, Salt Lake City, Utah 84132
}

Brainstem auditory neurons in the chick nucleus magnocellularis (NM) express high levels of the neuron-specific calciumbinding protein calretinin (CR). CR has heretofore been considered a diffusible calcium buffer that is dispersed uniformly throughout the cytosol. Using high-resolution confocal microscopy and complementary biochemical analyses, we have found that during the development of NM neurons, CR changes from being expressed diffusely at low concentrations to being highly concentrated beneath the plasma membrane. This shift in CR localization occurs at the same time as the onset of spontaneous activity, synaptic transmission, and synapse refinement in NM. In the chick brainstem auditory pathway, this subcellular

One of the most characteristic features of neurons is the degree to which specific functions are localized. The subcellular location of particular molecules within a neuron determines the contributions that these molecules can make to the overall function of the cell (Rosenmund et al., 1994; Steward, 1997; Ziff, 1997). For example, the precise localization of calcium channels at the presynaptic terminal determines many aspects of synaptic function, because calcium levels locally govern exocytotic neurotransmitter release (Augustine et al., 1987). Because other proteins also contribute to the regulation of calcium ion concentration, one might predict that such proteins, rather than being uniformly dispersed within a cell, might also be spatially localized. The present study focused on one such protein, the calcium-binding protein calretinin, in a class of auditory neurons that face unique calcium challenges.

Brainstem auditory neurons preserve the relative timing of action potentials transmitted through successive synaptic levels by means of unique morphological and functional adaptations in axons, dendrites, and synapses. These adaptations include rapidly desensitizing, calcium-permeable AMPA receptors, a strong $\mathrm{K}^{+}$ conductance to repolarize the cell rapidly, and large calycine axosomatic endings to facilitate reliable transmission (Oertel, 1999; Trussell, 1999). Because auditory neurons have some of the highest average and maximal discharge rates in the CNS, the presence of $\mathrm{Ca}^{2+}$-permeable synaptic receptors subjects them to

\footnotetext{
Received Nov. 22, 1999; revised Jan. 13, 2000; accepted Jan. 19, 2000.

This work was supported by US Public Health Service Grant DC00144 to T.N.P. and US Public Health Service grants NS24683 and NS37024 to S.B.K. We thank Dr. Chi-Bin Chien and Dr. Maureen Condic for critical reading of this manuscript; Dr. P. B. Guthrie, Dr. Laran Jensen, Dr. Mahendra Rao, and Dr. Lance Zirpel for many helpful discussions throughout the course of the project; and Mary Janowiak, Alan C. Peterson, and Dwan A. Taylor for expert technical assistance. We are grateful to Pam Reid and Dr. Carl Thummel for making their confocal microscope available to us.

Correspondence should be addressed to Dr. Nicola J. Hack, Department of Neurobiology and Anatomy, University of Utah School of Medicine, 50 North Medical Drive, Salt Lake City, UT 84132. E-mail: Nicola.Hack@hsc.utah.edu.

Copyright (C) 2000 Society for Neuroscience $\quad 0270-6474 / 00 / 200001-\bullet \$ 15.00 / 0$
}

localization appears to occur only in NM neurons and only with respect to $\mathrm{CR}$, because calmodulin remains diffusely expressed in NM. Biochemical analyses show the association of calretinin with the membrane is detergent-soluble and calciumindependent. Because these are highly active neurons with a large number of $\mathrm{Ca}^{2+}$-permeable synaptic AMPA receptors, we hypothesize that localization of CR beneath the plasma membrane is an adaptation to spatially restrict the calcium influxes.

Key words: calcium-binding proteins; auditory neurons; calcium homeostasis; calretinin; subcellular localization; nucleus magnocellularis

high calcium influxes and requires them to maintain a variety of mechanisms for maintaining calcium homeostasis (Zirpel et al., 1998). Calcium-binding proteins (CBPs) have been proposed to be particularly important for such calcium regulation because they are abundantly expressed in auditory neurons of both mammals and birds (Takahashi et al., 1987; Rogers, 1989; Parks et al., 1997). The cochlear nucleus magnocellularis (NM) in the chick is composed of neurons with all of the characteristic specializations of brainstem auditory neurons and whose anatomy, physiology, and development have been well characterized (Rubel and Parks, 1988; Oertel, 1999; Trussell, 1999).

Nucleus magnocellularis neurons express a single CBP, calretinin, and not the closely related E-F hand CBPs parvalbumin and calbindin (Parks et al., 1997). Calretinin, like parvalbumin and calbindin, has widely been thought to be a soluble protein that resides primarily in the cytosol, as a soluble buffer (Baimbridge et al., 1992; Andressen et al., 1993). We present evidence here that, during the development of NM neurons, calretinin shifts from being uniformly distributed throughout the cell body to being concentrated in a shell underlying the cell membrane. This change in localization coincides in developmental time with the onset of spontaneous electrical activity in the cochlea (Lippe, 1994), the onset of synaptic transmission from the cochlear nerve

This article is published in The Journal of Neuroscience, Rapid Communications Section, which publishes brief, peerreviewed papers online, not in print. Rapid Communications are posted online approximately one month earlier than they would appear if printed. They are listed in the Table of Contents of the next open issue of JNeurosci. Cite this article as: JNeurosci, 2000, 20:RC67 (1-5). The publication date is the date of posting online at www.jneurosci.org.

http://www.jneurosci.org/cgi/content/full/4042 
to NM neurons, and the condensation of cochlear nerve axons into large calycine axosomatic endings (Rubel and Parks, 1988). We propose that the change in calretinin localization allows NM neurons to function effectively under conditions of high cytoplasmic calcium load.

\section{MATERIALS AND METHODS}

Animals. Fertilized White Leghorn chicken eggs were obtained from a local supplier and incubated in forced draft incubators.

Immunohistochemistry and confocal microscopy. Embryonic chicks were anesthetized by intraperitoneal injection of sodium pentobarbital and then perfused transcardially with $0.9 \%$ saline followed by cold $4 \%$ paraformaldehyde (in $0.1 \mathrm{~m}$ phosphate buffer, $\mathrm{pH}$ 7.4). Brains were removed, post-fixed $\left(4^{\circ} \mathrm{C}\right)$ for $2-4 \mathrm{hr}$, and placed in $30 \%$ sucrose in $0.1 \mathrm{M}$ phosphate buffer for $24 \mathrm{hr}$. Embryos were staged according to the series of Hamburger and Hamilton (1951). Eighteen-micrometer sections were cut on a cryostat and mounted on gelatin-coated slides for immunohistochemistry. Calretinin immunoreactivity was detected with rabbit polyclonal antisera against human calretinin (Schwaller et al., 1993; SWant, Bellinzona, Switzerland) by using a tetramethylrhodamine isothiocyanate-tagged secondary antibody (Jackson ImmunoResearch, West Grove, PA). Because it has been reported that antibody recognition of calretinin can depend on its calcium binding status, some sections were stained with a calcium-insensitive antibody to calretinin (Winsky and Kuznicki, 1996). We saw no difference in staining pattern between the two antibodies. Sections were viewed on a BioRad (Hercules, CA) 1024 confocal microscope with a $60 \times$ oil objective. Optical sections every $2 \mu \mathrm{m}$ through the thickness of a cell were captured at fixed camera gain, pinhole size, and laser intensity.

Quantitative analysis of subcellular distribution of calretinin. Analysis of fluorescent intensity was performed on a Macintosh computer using the public domain NIH Image program (developed at the US National Institutes of Health and available on the Internet at http://rsb.info.nih.gov/nih-image/). Fluorescent intensities of a defined area $(2 \times 2$ pixels $)$ were measured at four locations at the perimeter of each cell and two locations within each cell avoiding the nucleus. The average intensity at the perimeter and the center of the cell was calculated and expressed as a ratio $\left(\mathrm{I}_{\text {perimeter }} / \mathrm{I}_{\text {center }}\right)$. Three animals were analyzed at each embryonic age: embryonic day 10 (E10; 27 cells), E13 (53 cells), E15 (58 cells), and E18 (55 cells).

Dissociation of nucleus magnocellularis neurons. NMs dissected from chick brainstem were placed in papain (Worthington Biochemicals, Lakewood, $\mathrm{NJ} ; 40 \mathrm{U} / \mathrm{ml}$ ) for $30 \mathrm{~min}$ at room temperature. Using a fire-polished pasteur pipette, NMs were triturated, and single cells were plated on poly-L-lysine-coated glass-bottomed dishes in MEM containing $10 \%$ fetal bovine serum (HyClone, Logan, UT). Four hours after plating, cells were fixed with $4 \%$ paraformaldehyde in $0.1 \mathrm{~m}$ phosphate buffer, $\mathrm{pH} 7.4$, containing $0.12 \mathrm{~m}$ sucrose. Cells were immunostained for calretinin and viewed under a confocal microscope.

Immunoblot analysis. NMs were dissected from chickens at various embryonic ages and homogenized in a harvesting buffer containing 62.5 $\mathrm{mm}$ Tris-HCl, $\mathrm{pH}$ 6.9, $2.3 \%$ SDS, $10 \%$ glycerol, and 2 mM EDTA. Seventy micrograms of total protein (estimated with the BCA method) were subjected to SDS-PAGE according to the method of Laemmli (1970). One hundred nanograms of calretinin (in vitro translated and purified using a glutathione $S$-transferase purification system; Pharmacia Biotech, Uppsala, Sweden) was run as an internal control. Proteins were transferred to nitrocellulose membranes, and immunoblotting was performed in the presence of $0.5 \%$ nonfat dry milk and $0.1 \%$ Tween 20 in $0.01 \mathrm{~m}$ phosphate buffer, $\mathrm{pH}$ 7.5. Antisera against calretinin (SWant) or $\beta$-actin (Sigma, St. Louis, MO) were used at 1:10000 or 1:5000, respectively. Detection of bound antibody was done using an ECL detection system (Amersham, Piscataway, NJ).

Preparation of subcellular fractions. Subcellular fractions of chick brainstem were obtained by differential centrifugation. Chick brainstem pieces containing the nucleus magnocellularis were harvested in $5 \mathrm{~mm}$ HEPES, $\mathrm{pH} 7.4$, containing $0.32 \mathrm{M}$ sucrose, $0.2 \mathrm{~mm}$ calcium chloride, and a mixture of protease inhibitors (Sigma). Tissue was homogenized on ice with a Teflon pestle ( 20 strokes) followed by a glass pestle ( 40 strokes). The nuclear fraction was removed by a low-speed spin at $1000 \times g$ for 10 min. The resultant supernatant was centrif uged at $9800 \times g$ for 20 min to obtain a crude membrane pellet and a cytosolic supernatant. The pellet was washed by resuspension in $5 \mathrm{~mm}$ HEPES, $\mathrm{pH} 7.4$, containing $1.5 \mathrm{M}$ sucrose to lyse any unbroken cells, followed by centrifugation to remove

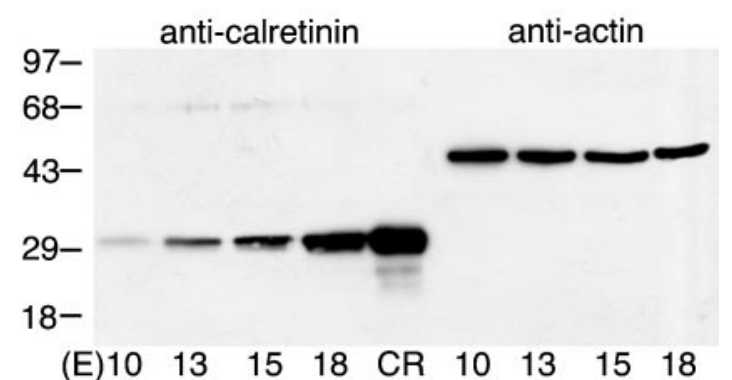

Figure 1. The concentration of calretinin increases during development. A representative Western blot of NM proteins shows an increase in calretinin concentration with embryonic age $(n=3$ independent experiments). Purified calretinin ( $C R)$ was run as a control, and migration of molecular weight markers is indicated on the left. Actin immunoblots of the identical samples indicate that equal amounts of protein were loaded in each lane.

any remaining cytosolic components. Aliquots of membrane and cytosolic fractions were subjected to SDS-PAGE and then immunoblotted (as above). To characterize the solubilization properties of calretinin, the membrane pellet was incubated in $2 \%$ Triton X-100 for $10 \mathrm{~min}$ at $4^{\circ} \mathrm{C}$ and recentrifuged. The resultant supernatant and pellet were subjected to SDS-PAGE and immunoblotted for calretinin.

\section{RESULTS}

We have shown previously that both calretinin transcript and immunoreactivity increase in chick NM neurons during development (Parks et al., 1997). The previous study provided us with important temporal information regarding calretinin expression in the auditory system, but the immunohistochemical techniques used to detect calretinin were not optimal for providing quantitative information. Here, we used a biochemical approach to obtain a measure of the relative concentration of calretinin in $\mathrm{NM}$ at the same developmental stages used previously. Western blot analysis of NM proteins isolated from chicks at embryonic days $10,13,15$, and 18 clearly showed an increase in calretinin concentration with age (Fig. 1). Calretinin expression was barely detectable at E10 but increased dramatically by E13 and continued to increase until E18. To perform single-cell analysis and determine the subcellular location of calretinin, we used immunofluorescence labeling of calretinin in NM slices, together with confocal microscopy. To our surprise, the subcellular location of calretinin within NM neurons changed as a function of developmental age. At E10, calretinin was expressed at low levels, in agreement with our biochemical analysis, and diffusely throughout the NM neuron, in agreement with other reports on calretinin immunohistochemistry (Rogers, 1989). By E15, however, calretinin was less homogeneous in its subcellular distribution, and an accumulation of immunofluorescence was observed underneath the plasma membrane in $86 \%$ of the cells examined (Fig. 2A). This submembrane distribution was even more pronounced at E18 when the majority of the cells $(91 \%)$ contained high levels of immunofluorescence in the form of a distinctive shell under the plasmamembrane. At posthatching day 2, the animals showed the same distribution of calretinin (results not shown), showing that the effect persists into postnatal life. Using the confocal microscope to obtain thin optical sections throughout the entire thickness of each NM neuron, we saw the characteristic ring-like distribution of calretinin in all optical sections, with the exception of the top and bottom sections that contain areas directly underneath the plasma membrane. To rule out staining artifacts and to determine whether the observed localization of calretinin was 
A
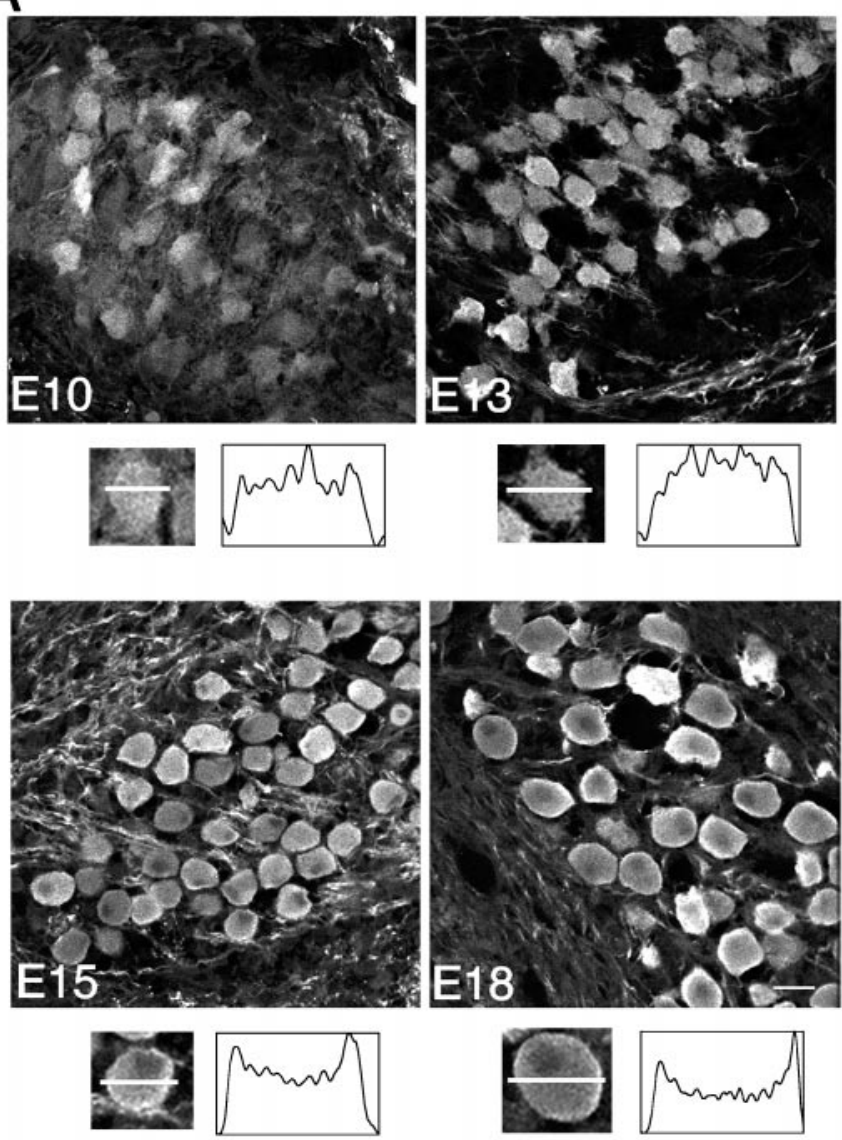

B
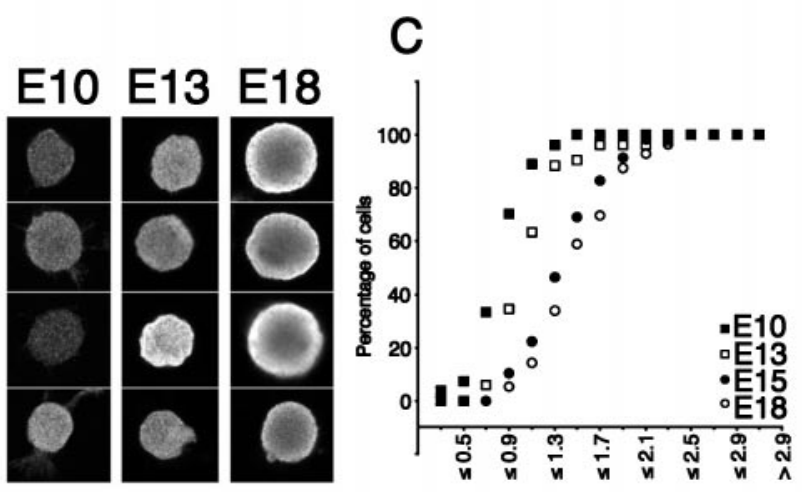

Ratio $\mathrm{I}_{\mathrm{p}} \mathrm{l}_{\mathrm{C}}$

Figure 2. A, Confocal images of chick NM at embryonic days 10, 13, 15, and 18 immunostained with a calretinin antibody show a dramatic shift in the distribution of calretinin from being diff use at E10 to being highly concentrated at the plasma membrane at E18. Line scans across individual cells show the spatial distribution of calretinin labeling at the four ages. Scale bar, $20 \mu$ M. $B$, Acutely dissociated NM cells were prepared from chick brainstem at the stated embryonic ages and immunostained for calretinin. Confocal images of four representative cells show an increase in labeling with age in addition to the change in distribution of calretinin as observed in vivo. $C$, Quantification of the change in subcellular distribution of calretinin was performed as described in Materials and Methods. The data are depicted in the form of a cumulative frequency histogram of ratio values $\left[\mathrm{I}_{\text {perimeter }} / \mathrm{I}_{\text {center }}\left(I_{p} / I_{c}\right)\right]$ measured from NM neurons during development.

influenced by the surrounding tissue, we isolated single NM neurons and placed them in a culture dish to allow uniform access of antibody to the cells. The results closely mirrored the results from tissue slices. NM neurons from E10 and E13 chicks were smaller and less intensely stained for calretinin than their E18 counterparts (Fig. 2B), and E18 neurons showed the most dramatic localization of calretinin. Furthermore, removal of afferent input through acute dissociation of these cells had no effect on the subcellular distribution of calretinin. To obtain semiquantitative measurements of the change in subcellular distribution of calretinin during NM development, we measured fluorescence intensities of NM neurons in calretinin-stained tissue slices, at the edge of the cell and in the center of the cell (see Materials and Methods). These values were expressed as a ratio, $\mathrm{I}_{\text {perimeter }} /$ $I_{\text {center }}$, and the ratio values were plotted as a cumulative frequency histogram for the four developmental ages (Fig. $2 C$ ). The frequency histogram clearly shows a difference in calretinin distribution between the cell populations of E10-E13 chicks and E15-E18 chicks. As predicted for a uniform homogeneous distribution of calretinin, $54 \%$ of the E13 cells displayed a ratio of 1, whereas $>90 \%$ of the E18 cells had $\mathrm{I}_{\text {perimeter }} / \mathrm{I}_{\text {center }}$ of $>1$; these ratios were reliably different $(p<0.01)$.

During development, NM neurons increase in volume together with their subcellular organelles (Fig. 2; Parks, 1979). To exclude the possibility that the change in localization may be attributable to a physical restriction of cytoplasm and cytosolic proteins to the periphery of the cell, we stained NM neurons with an antibody against the cytosolic protein calmodulin. In contrast to calretinin, confocal analysis showed that calmodulin immunoreactivity was homogeneously distributed throughout the neuron (Fig. 3a,b) with the exception of the nucleus. To examine whether calretinin was distributed similarly in other neurons, we examined two avian brainstem auditory nuclei, nucleus angularis (NA) and nucleus laminaris (NL), which are known to express calretinin (Parks et al., 1997). Neurons in both nuclei indeed stained for calretinin, but in contrast to NM neurons, calretinin was homogeneously distributed throughout NA and NL cells (Fig. $3 c, d$ ).

To confirm the observations obtained with the confocal microscope, we prepared subcellular fractions of chick brainstem by differential centrifugation (see Materials and Methods). Western blot analysis demonstrated that calretinin immunoreactivity was associated with both cytosolic and particulate fractions (Fig. 4A). Calretinin immunoreactivity in the particulate fraction resisted several washes, suggesting that the particulate localization did not reflect contamination from the cytosolic fraction. Densitometric measurements of band intensities using the NIH Image analysis program determined that $60 \pm 7 \%(n=5$ independent experiments) of calretinin immunoreactivity was associated with the particulate fraction. This estimation is likely to be an underestimate because, due to the small size of NM, our fractionation procedure required the use of whole brainstem pieces containing not only NM but also NL and NA. Confocal analysis of NL and NA neurons revealed homogeneous staining of calretinin, which implies that it would contribute only to our cytosolic fraction.

Previous studies on rat cerebellum estimated that no more than $10 \%$ of calretinin was membrane-associated (Winsky and Kuznicki, 1995). Therefore, we made cytosolic and membrane fractions from E18 chick cerebellum and ran the fractions under the same conditions as the brainstem and, in agreement with Winsky and Kuznicki (1995), we found that cerebellum calretinin is predominantly cytosolic (Fig. $4 A$ ). To examine the nature of the membrane association of brainstem calretinin, we manipu- 

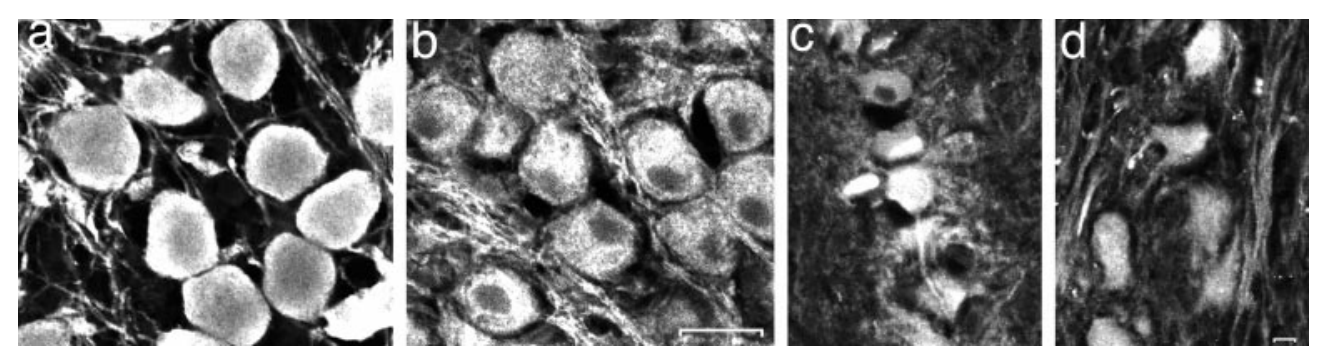

Figure 3. Other antigens, such as calmodulin (b), remain diffuse throughout NM neurons at E18, a developmental stage when calretinin becomes highly concentrated under the plasma membrane $(a)$. Scale bar, $20 \mu \mathrm{m}$. Confocal images of nucleus laminaris $(c)$ and nucleus angularis $(d)$ immunostained for calretinin at E18 show diffuse, homogeneous staining of calretinin. Scale bar, $10 \mu \mathrm{m}$.
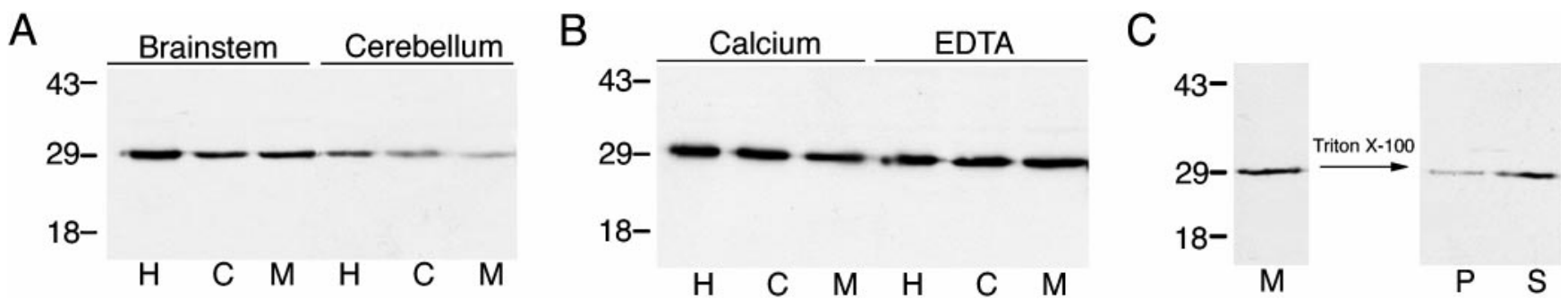

Figure 4. A, Western blot for calretinin of subcellular fractions prepared from E18 chick brainstem and cerebellum as described in Materials and Methods. $H$, Homogenate; $C$, cytosol; $M$, membrane. A significantly higher proportion of calretinin remains associated with the membrane after subcellular fractionation of brainstem compared with cerebellum. This was repeated three times with identical results. $B$, Subcellular fractions of E18 chick brainstem prepared in the presence or absence of calcium ( $2 \mathrm{mM} \mathrm{CaCl}_{2}$ or $1 \mathrm{~mm}$ EGTA, respectively) did not alter the proportion of immunoreactive calretinin found in the membrane fraction $(C)$. Treatment of the membrane fraction with $2 \%$ Triton X-100 released calretinin into the supernatant $(S)$ with little immunoreactivity remaining in the pellet $(P)$. Migration of molecular weight markers is indicated on the left.

lated the conditions under which the particulate fraction was prepared. Several calcium-binding proteins are known to undergo calcium-dependent interactions with the plasma membrane (Dizhoor et al., 1993; Meyers et al., 1995; Lenz et al., 1996). Therefore, we removed all extracellular calcium during subcellular fractionation of brainstem proteins by including EGTA in the homogenization buffer. Calcium had no influence on the distribution of immunoreactive calretinin across fractions (Fig. 4B). In addition, treatment of the membrane fraction with the detergent Triton X-100 released the majority of the calretinin from the pellet (Fig. 4C). The nearly complete solubility in Triton X-100 suggested that calretinin is unlikely to be associated with the cytoskeleton.

\section{DISCUSSION}

We have shown that during development of NM neurons, calretinin changes from being uniformly distributed and at low concentrations to being highly concentrated under the plasma membrane. Previous biochemical estimates indicated that in cerebellum (Winsky and Kuznicki, 1995) and whole brain (Hubbard and McHugh, 1995), <10 and 27\%, respectively, of calretinin is associated with the particulate fraction. Our biochemical data show that $\sim 60 \%$ of total brainstem calretinin is localized to the particulate fraction (and significantly $>60 \%$ of NM calretinin). The functional consequences of a CBP being localized to the plasma membrane, as opposed to freely mobile within the cytosol, are considerable. The action of calcium ions in the cytosol is constrained by many effectors of calcium buffering and removal, including CBPs (Miller, 1991). The spatial localization of these effectors will, in turn, affect the behavior, both temporally and spatially, of a calcium signal within a neuron (see below).

Other CBPs have been found to be localized under the plasma membrane (calcineurin; Lukyanetz, 1997) or directly associated with the plasma membrane [S100 (Donato et al., 1989), recoverin (Dizhoor et al., 1993), and visinin-like protein (VILIP) (Lenz et al., 1996)]. Unlike calretinin, in some cases this interaction is dependent on the cytoskeleton or on intracelluar calcium levels [recoverin (Dizhoor et al., 1993), VILIP (Lenz et al., 1996), caldendrin (Seidenbecher et al., 1998), and neuronal calcium sensor-1 (Martone et al., 1999)]. Although functional significance of these associations for calcium signaling has not been directly tested, the theoretical implications are important. During normal physiology NM neurons experience unusually high calcium influxes directly at the cell soma (Trussell, 1999). Because the estimated $K_{\mathrm{d}}$ of calretinin for calcium is $380 \mathrm{~nm}$ (Stevens and Rogers, 1997), most of the calretinin should be in an unbound state at resting calcium levels, enabling it to function during periods of elevated calcium. In addition, localizing calretinin to underneath the site of high calcium influx would presumably attenuate global rises in cytosolic calcium because of its ability to bind calcium. Because our biochemical analysis suggests that calretinin is associated with the membrane and therefore likely immobile, one would predict that calretinin would act to lower the diff usion of calcium ions through the cytosol (Gabso et al., 1997). Although calretinin is clearly not the only effector of calcium buffering and removal in NM neurons, its position under the membrane places it spatially to interact with membraneassociated calcium extrusion pumps. Conversely, calcium ions released from intracellular sites would be relatively unaffected by the high concentration of calretinin at the membrane.

Although calretinin expression levels are not influenced by removal of afferent input or the onset of synaptogenesis (Parks et al., 1997; Kubke et al., 1999) the developmental period over which calretinin becomes localized correlates conspicuously with the formation of the mature calycine synapse and the onset of mature 
activity patterns (Rubel and Parks, 1988; Lippe, 1994). It is intriguing to speculate that the developmentally regulated localization of calretinin is an activity-dependent phenomenon not dissimilar to the activity regulated positioning of other proteins (Tongiorgi et al., 1997; Craig, 1998; Steward et al., 1998). Alternatively, localization of calretinin may equally be influenced by the formation of the presynaptic calyx or expression of postsynaptic AMPA receptors.

The message of the present investigation is that calretinin can be, at a given time in development, highly localized. We hypothesize that localization of calretinin beneath the plasma membrane is an adaptation of NM neurons to spatially restrict calcium influxes. Given the tools at hand and the potentially large functional consequences, it may be important to reevaluate the spatial disposition of calcium-binding proteins in other regions of the nervous system during development.

\section{REFERENCES}

Andressen C, Blümcke I, Celio MR (1993) Calcium-binding proteins: selective markers of nerve cells. Cell Tissue Res 271:181-208.

Augustine GJ, Charlton MP, Smith SJ (1987) Calcium action in synaptic transmitter release. Annu Rev Neurosci 10:633-693.

Baimbridge KG, Celio MR, Rogers JH (1992) Calcium-binding proteins in the nervous system. Trends Neurosci 15:303-308.

Craig AM (1998) Activity and synaptic receptor targeting: the long view. Neuron 21:459-462.

Dizhoor AM, Chen C-K, Olshevskaya E, Sinelnikova VV, Phillipov P, Hurley JB (1993) Role of the acylated amino terminus of recoverin in $\mathrm{Ca}^{2+}$-dependent membrane interaction. Science 259:829-832.

Donato R, Giambanco I, Aisa MC, Ceccarelli P (1989) Identification of S-100 proteins and S-100-binding proteins in a detergent-resistant EDTA/KCl-extractable fraction from bovine brain membranes. FEBS Lett 247:31-35.

Gabso M, Neher E, Spira ME (1997) Low mobility of the $\mathrm{Ca}^{2+}$ buffers in axons of cultured Aplysia neurons. Neuron 18:473-481.

Hamburger V, Hamilton HL (1951) A series of normal stages in the development of the chick embryo. J Morphol 88:49-92.

Hubbard MJ, McHugh NJ (1995) Calbindin $28 \mathrm{kDa}$ and calbindin $_{30 \mathrm{kDa}}$ (calretinin) are substantially localised in the particulate fraction of rat brain. FEBS Lett 374:333-337.

Kubke FM, Gauger B, Basu L, Wagner H, Carr CE (1999) Development of calretinin immunoreactivity in the brainstem auditory nuclei of the barn owl (Tyto alba). J Comp Neurol 415:189-203.

Laemmli UK (1970) Cleavage of structural proteins during the assembly of the head of bacteriophage T4. Nature 15:680-685.

Lenz SE, Braunewell K-H, Weise C, Nedlina-Chittka A, Gundelfinger ED (1996) The neuronal EF-hand $\mathrm{Ca}^{2+}$-binding protein VILIP: interaction with cell membrane and actin-based cytoskeleton. Biocehm Biophys Res Commun 225:1078-1083.

Lippe WR (1994) Rhythmic spontaneous activity in the developing avian auditory system. J Neurosci 14:1486-1495.

Lukyanetz EA (1997) Evidence for colocalization of calcineurin and calcium channels in dorsal root ganglion neurons. Neuroscience 78:625-628.

Martone ME, Edelmann VM, Ellisman MH, Nef P (1999) Cellular and subcellular distribution of the calcium-binding protein NCS-1 in the central nervous system of the rat. Cell Tissue Res 295:395-407.
Meyers MB, Zamparelli C, Verzili D, Dicker AP, Blanck TJJ, Chiancone E (1995) Calcium-dependent translocation of sorcin to membranes: functional relevance in contractile tissue. FEBS Lett 357:230-234.

Miller RJ (1991) The control of neuronal $\mathrm{Ca}^{2+}$ homeostasis. Prog Neurobiol 37:255-285.

Oertel D (1999) The role of timing in the brain stem auditory nuclei of vertebrates. Annu Rev Physiol 61:497-519.

Parks TN (1979) Afferent influences on the development of the brain stem auditory nuclei of the chicken: otocyst ablation. J Comp Neurol 383:112-121.

Parks TN, Code RA, Taylor DA, Solum DA, Strauss KI, Jacobwitz DM, Winsky L (1997) Calretinin expression in the chick auditory nuclei develops and is maintained independently of cochlear nerve input. J Comp Neurol 383:112-121.

Rogers JH (1989) Two calcium-binding proteins mark many chick sensory neurons. Neuroscience 31:697-709.

Rosenmund C, Carr DW, Bergeson SE, Nilaver G, Scott JD, Westbrook GL (1994) Anchoring of protein kinase A is required for modulation of AMPA/kainate receptors on hippocampal neurons. Nature 368:853-856

Rubel EW, Parks TN (1988) Organization and development of the avian brainstem auditory system. In: Auditory function: neurobiological bases of hearing. (Edelman GM, Gall WE, Cowan WM, eds), pp 3-92. New York: Wiley.

Schwaller B, Buchwald P, Blumcke I, Celio MR, Hunziker W (1993) Characterization of a polyclonal antiserum against the purified human recombinant calcium binding protein calretinin. Cell Calcium 14:639-648.

Seidenbecher CI, Langnaese K, Sanmartí-Vila L, Boecker TB, Smalla K-H, Sabel BA, Garner CC, Gundelfinger ED, Kreutz MR (1998) Caldendrin, a novel neuronal calcium-binding protein confined to the somato-dendritic compartment. J Biol Chem 273:21324-21331.

Stevens J, Rogers JH (1997) Chick calretinin: purification, composition, and metal binding activity of native and recombinant forms. Protein Expr Purif 9:171-181.

Steward O (1997) mRNA localization in neurons: a multipurpose mechanism? Neuron 18: 9-12.

Steward O, Wallace CS, Lyford GL, Worley PF (1998) Synaptic activation causes the mRNA for the IRG Arc to localize selectively near activated postsynaptic sites on dendrites. Neuron 21:741-751.

Takahashi TT, Carr CE, Brecha N, Konishi M (1987) Calcium binding protein-like immunoreactivity labels the terminal field of nucleus laminaris of the barn owl. J Neurosci 7:1843-1856.

Tongiorgi E, Righi M, Cattaneo A (1997) Activity-dependent dendritic targeting of BDNF and TrkB mRNAs in hippocampal neurons. J Neurosci 17:9492-9505.

Trussell LO (1999) Synaptic mechanisms for coding timing in auditory neurons. Annu Rev Physiol 61:477-496.

Winsky L, Kuznicki J (1995) Distribution of calretinin, calbindin D28k, and parvalbumin in subcellular fractions of rat cerebellum: effects of calcium. J Neurochem 65:381-388.

Winsky L, Kuznicki J (1996) Antibody recognition of calcium-binding proteins depends on their calcium-binding status. J Neurochem 66:764-771.

Ziff EB (1997) Enlightening the postsynaptic density. Neuron 19:1163-1174.

Zirpel L, Lippe WR, Rubel EW (1998) Activity-dependent regulation of $\left[\mathrm{Ca}^{2+}\right]_{\mathrm{i}}$ in avian cochlear nucleus neurons: roles of protein kinases A and $\mathrm{C}$ and relation to cell death. J Neurophysiol 79:2288-2302. 